\title{
Interactive Minds - \\ A Paradigm for the Study of the Social-Interactive Nature of Human Cognition and its Lifespan Development ${ }^{1}$
}

\section{Ursula M. Staudinger and Markus Joos}

After a brief review of historical and contemporary trends in the study of the socialinteractive nature of cognition, a definition of the interactive minds paradigm is presented. Cognition is social-interactive in nature in at least three respects (a) its cultural evolution as well as its ontogeny, (b) its activation and application, and (c) its recognition. But is it true that two heads are better than one? An empirical «interactive minds" paradigm was developed and tested using the sample case of wisdom-related performance. Five performance settings were developed which differed in the ratio of individual and interactive cognition and its ecological relevance. Results revealed that the condition combining individual and interactive cognition, that is, dialogue and appraisal, was most facilitative for the activation of wisdom-related knowledge and judgment. Thus, not any interactive cognition seems to be facilitative but rather a sequential combination of both individual as well as interactive cognition.

The social character of the human mind and human behavior has long been acknowledged. Probably one of the first «experimental studies» in this respect was conducted by the German Emperor Friedrich II in 12th century. He wanted to investigate the question which language neonates would develop, if they were raised without social context. Would it be Hebrew, Latin, Greek or the mother tongue of his/her parents? The sad result of his study is well known - all neonates had died before they were able to even speak one word (Francescato, 1973).

Human behavior develops in transaction with social forces. The social or contextual embeddedness of the human mind seems to constitute an important facet of the conditio humana. Dating back as far as to the sixth century BC, Heraklit has pointed out in his work "The Nature»: "Although the sense is one of a common mind, most live as if they would have their own reason». Already at the beginnings of modern psychology we can find dialectic views on the relation between the individual and the collective, as illustrated in the writings of William James, John Dewey and George Herbert Mead. In the work of George Herbert Mead, for instance, James' functionalism led to the formation of symbolic interactionism. This trend can also be found in late 19th century sociology. It was 
Durkheim who discussed the social dependencies of thought and knowledge. Later such ideas were taken up again, for instance, in Moscovici's social psychology. Bartlett was probably the first in cognitive psychology who seriously considered the social nature of cognition when formulating his schema-theory of memory.

In experimental social psychology the investigation of effects of social context on behavior and learning can be traced back to an early study by Triplett in 1897. He demonstrated that the speed of bike-riding was higher when riding in a group than when riding alone. Turning from cognitive and social psychology to developmental psychology, the origins of socio-genetic thinking can be traced back to the often neglected French psychiatrists Pierre Janet and his contemporary James Baldwin. Janet and Baldwin had strong influences on the succeeding generation of socio-genetic thinkers such as Piaget and Vygotsky. After these beginnings, the investigation of the social nature of cognition has been revived in the 70s of this century. In developmental psychology this is linked to scholars like Riegel and his dialectic psychology or Bronfenbrenner's ecological model of development and the beginnings of lifespan psychology (Baltes, Rees, and Lipsitt, 1980). Similarly, the interactionism debate, with its call for more explicit consideration of interactive and transactional conceptions in various fields of psychology, has to be mentioned in this context (e.g., Endler and Magnusson, 1976).

More recently, several concepts linked to the social character of human mind and behavior have emerged. Concepts, such as shared knowledge, mutual knowledge, situated cognition, distributed cognition, social mind, collaborative memory, group processes in cognition, socially situated cognition, cooperative cognition, highlight the role of social interaction in the development, activation and evaluation of cognition (e.g., Baltes and Staudinger, 1996; Bar-Tal and Kruglanski, 1988; Bornstein and Bruner, 1989; Dixon, 1992; Levine; Resnick, and Higgins, 1993; Resnick, Levine, and Teasley, 1991; Sternberg, and Wagner, 1994; Wozniak and Fischer, 1993; Wyer and Srull, 1986). Most of the recent approaches to the social-interactive nature of the mind stress the importance of extending existing empirical paradigms beyond the isolated individual. They suggest incorporating the collective and social-interactive facets of human mind and behavior, thereby opening new prospects on the study of cognition. Despite this insight and call for new paradigms there still is a mismatch between theory and empirical study.

One persuasive exception is the enrichment and transformation of sociallearning theory by cognitive dimensions to better understand the social and collective foundations of action and thought (e.g., Bandura, 1986). Another ongoing search for a better representation of collective and social-interactive perspectives in psychology is the recent stream of «postmodern» efforts to articulate reality as social construction (Neimeyer, Neimeyer, Lyddon and Hoshmand, 1994). To be mentioned also are recent debates about collectivism versus 
individualism (Miller and Prentice, 1994). The recent revival of interest in the social-interactive nature of human cognition is also illustrated by several review articles and edited volumes (e.g., Bar-Tal and Kruglanski, 1988; Bornstein and Bruner, 1989; Cohen and Siegel, 1991; von Cranach, Doise, and Mugny, 1992; Forman, Minick, and Stone, 1993; Levine, Resnick, and Higgins, 1993; Light and Butterworth, 1992; Resnick, Levine, and Teasley, 1991; Rogoff and Chavajay 1995; Sternberg and Wagner, 1994; Wozniak and Fischer, 1993).

\section{Theoretical Perspectives on Interactive Minds and Lifespan Development}

\section{Interactive Minds - a New Metaphor}

In the present article, we focus on the concept of interactive minds, that is one of the recent terms denoting the social nature of human cognition (Baltes and Staudinger, 1996). For three interrelated reasons, it was decided to introduce still another concept: (1) to keep open the outcome directionality and valence of social interaction, (2) to coin a metaphor with effective imagery implicating social interaction and transaction, and (3) to preserve the unique psychological emphasis on individuals as the basic units of interaction.

(1) The search was for a term, while clear in its social-interactive meaning, that was unbiased as to the direction and the valence of the performance outcome. Despite the fact that it was believed that social interaction (over different domains as well as ontogenetic time) in general enhances performance, a lot of research literature demonstrates, that not all social interactive conditions improve performance (e.g., Hill, 1982; Stroebe, Diehl, and Abakuomkin, 1992). There are many possibilities why people may not effectively interact with each other, among those reasons are motivational reasons or distraction due to attentional load, differences between the interactive partners in level of functioning, differences in knowledge or talent, or incompatibilities in styles of problem solving. Furthermore, issues associated with the proper sequencing and combination of social transactions in the problem-solving process, with person-centered phases of activity, are of concern. Differences in the nature of cognitive tasks lead to different expectations about the degree of performance improvement through social interaction (Staudinger, 1996). Also genetic arguments may account for directional openness of performance outcomes within social transactions. The evolutionary-psychological approach to the study of mind (Barkow, Cosmides, and Tooby, 1992) can be viewed as an example. This approach emphasizes that phylogenetic earlier adaptations of human-environment transaction, due to their relatedness to space and context, may have involved brain-related dispositions that may not be functional in today's world. Gains and losses that arise from social interactions, then, can have their origin both in evolution-based genetic predispositions as well as in the constellation of performance factors that define a 
given social transaction during ontogenesis and microgenesis of intellectual performance.

(2) The second reason for introducing the term interactive minds was the search for a concept with good metaphorical properties because metaphors have been shown to be powerful regulators and modulators of theoretical efforts in psychology (Leary, 1990) as well as in cognitive development in particular (Sternberg, 1990a).

(3) The third reason for finding a new metaphor was that although identifying at least three metaphors (the epistemological, sociological, and the anthropological) that are concerned with the role of social interaction in the evolution and ontogenesis of mind, none of these metaphors is specifically focused on social-cognitive interaction. Moreover, the two metaphors closest to and most explicit in their social orientation in evolution and ontogenesis, the sociological and anthropological ones, lie outside the field of psychology. Since psychology seeks a unique location in the spectrum of behavioral and social sciences with its own person- and behavior-centered concepts and empirical methods of inquiry and since the basic units for psychological theory and research are individuals and their mind-based resources, it was important to look for a metaphor that makes explicit the individual-level focus of psychology but at the same time suggests the social characteristics of mind.

\section{Interactive Minds in the Context of the Propositions of Lifespan Psychology}

The notion of interactive minds is closely linked to lifespan psychology, which will be illustrated next. Lifespan psychology can be described as metatheory consisting of a family of guiding propositions or principles about the nature of human ontogenesis and about the ways how to best study it (e.g., Baltes, 1987). Lifespan theory provides perspectives that are consistent with arguments about the role of social and cultural factors in human behavior advanced by other research traditions such as cultural psychology (see also Boesch, 1991). Based on the commitment of lifespan theory to the social nature of human development, we find a strong interest of lifespan researchers in social-interactive paradigms (e.g., Baltes, and Staudinger, 1996, Dixon and Gould, 1996). Lifespan psychology can be described by six major propositions (see also Baltes, Staudinger, and Lindenberger, 1999):

The first proposition that human development extends from conception through death, hints at the variety of contexts and social transactions in which cognitive development and cognitive functioning can take place. As to the study of interactive minds, a lifespan view provides a first look at the sequencing and patterning of social interactions, as they occur at one point in time as well as in sequence including such interaction partners as parents and kin, peers, teachers, colleagues, friends, life companions, marriage partners, and staff in care institutions, and their relative impact at different points in the life course. The second 
notion of the multidimensionality and multidirectionality of developmental trajectories suggest that the quality and effectiveness of interactions can vary between types of interactions (e.g., parents vs. peers), and that interactive functioning in earlier life phases may involve protective and risk conditions for later stages of the life course. One may consider for instance the structure and function of social networks that as convoys (Kahn and Antonucci, 1980) generate a matrix of interactive minds across the life course. The third proposition of simultaneity of gains and losses in development points to the view that development is neither mere growth nor mere decline but rather multifunctional (M. Baltes, 1995). For instance as children acquire their mother tongue, they experience some recognition and production losses regarding sounds not contained in their primary language. The fourth proposition of plasticity in human development points to the question of the "zone» or "norm of reactions» of possible development and to the role of social factors contributing to this. Thus one may ask, in which way interactive minds can and do optimize the activation of latent potential, or to what degree are dysfunctions or lacking abilities compensated for by the interaction between minds? The last two propositions, historical embeddedness and contextualism stress not only the important role of individual, social and cultural context but also the consideration of contexts of human development along spatial and temporal dimensions.

\section{Towards an Empirical Paradigm to Study Interac- tive Minds}

Interactive minds refers to "the acquisition and manifestation of individual cognitions that influence and are influenced by cognitions of others and that these reciprocal influences between minds contribute to the activation and modification of already available cognitions as well as to the generation (development) of new ones» (Baltes and Staudinger, 1996, p. 7). Four aspects of interactive minds need to be taken into account when attempting to study the social nature of social cognition: (1) proximity of interaction, (2) level of manifestation, (3) prerequisites, and (4) evaluative criteria.

\section{Proximity of the Interaction}

First, we have to consider that calling an interaction social is not precise enough. It is necessary to clarify the degree of proximity of the interaction. The basic distinction is one between two different types of interaction: direct interaction and indirect interaction. Direct interaction refers to an interaction setting where one or more interaction partners are physically present. Thus, interaction partners can actively collaborate or are physically present. Investigations by social psychologists concerned with group problem solving and social facilitation are good examples of these two different kinds of direct interaction. Indirect interaction refers to the situation when interaction partners are not physically present but 
the interaction between partners is symbolically mediated. On the distal end of this dimension, symbolically mediated interaction takes place between the person and what cultural anthropologists call cultural artifacts (e.g., Cole, 1996) of any kind, such as objects, written material or institutional structures. The second meaning of symbolically mediated interaction is interaction that takes place within a person's head by means of mental representations about another person. These mental representations can refer to the future, the past or an ideal. An increasing number of studies has demonstrated that mental representations can have strong qualitative as well as quantitative effects on the cognitive performance of an individual (e.g., Staudinger, 1996).

\section{Level of Manifestation}

The second aspect of interactive minds refers to the different levels on which interactive cognitions may take place. First, interactive cognitions may have left their traces in the history of human kind, that is in the evolution of the human mind. This is probably a source of influence which is often neglected. But second, social interaction, in its varying degrees of proximity, plays a crucial role in the ontogenesis of an individual. And finally interactive cognitions are important for the microgenesis of cognitive outcomes. Referring to the evolutionary basis of social cognition, Barkow, Cosmides and Tooby (1992) argue that human beings belong to one of the rare species which conduct reciprocal altruism and that this had led to specific cognitive structures and functions. For instance, the human mind seems to be well prepared to discover violations of the basic rules of reciprocal altruism, for instance if a person claims advantages without refunding anything. Cosmides (1989) as well as Gigerenzer (1996) argue furthermore that the human brain may have several of such modules for different areas of cognition. Child developmental research supports this assumption with the finding that infants first learn to decide whether they want to interact with a living or non-living object and based on this decision apply a different logic respectively. Along these lines, one could examine if the four kinds of human sociality described by Fiske (1992) come along with such cognitive modules as they were suggested by evolutionary psychologists. Fiske distinguishes between (1) communal sharing, i.e. same dealing for all interaction partners, (2) authority ranking, (3) equality matching, i.e. a relation that is orientied towards equality in taking and giving, and finally (4) market pricing, i.e. people orient their interaction according to offerings and demand.

From evolution to ontogenesis: What role does direct interaction, as described above, play in cognitive development? Research concerned with peer and child adult interaction has revealed that children who have not yet developed communicative and collaborative skills gain less and less from social interaction as task difficulty increases. For young children social interaction and task effort are a kind of a dual-task setting. One can even find that children are only concerned with solving the task while completely forgetting the interaction. It is 
only with older children and in adolescence that the gain from social interaction is less dependent of task difficulty (e.g., Azmitia, 1996). Azmitia and Perlmutter (1989) proposed five mechanisms which they suggest influences cognitive development during social interactions: Imitation, conflict, dealing, guidance and coconstruction. Implicit in this order is first the varying importance of these mechanisms at different life stages and their differential impact on various kinds of learning. Research on the impact of social interaction on cognitive ontogenesis is one of the few examples which led to concepts of intervention such as the concept of reciprocal teaching suggested by Brown and others (1992). Turning from the beginning of life span development to advanced age, so far only few studies have investigated the influence of social interaction on cognitive development in adulthood and old age. Most likely during ontogeny of the human mind, a history of social interactions influence a person's knowledge and way of thinking that supports the adaptive interaction with cognitive demands. It is also possible that task demands are split between members of a cognitive network which can in turn lead to one person's further development or diminution of cognitive abilities. Support for this assumption, for instance, comes from investigations of transactive memory (Wegner, Erber and Raymond, 1991) which revealed that such adaptive distribution of work in married couples takes place and that in turn dissolution of these couples at first leads for both partners to the experience of deficiencies in knowledge and abilities. In old age, direct and indirect social interactions can be seen as an important support factor in the face of declining abilities, especially in the area of fluid abilities or cognitive mechanics. Interaction partners can mutually take over compensating functions.

\section{Prerequisites and Process}

The third dimension of interactive minds is concerned with the prerequisites of the microgenesis of social interactions. For instance, it is important that each partner has the necessary cognitive prerequisites to be able to perform the different phases of the interaction. Also the personality structure influences the process and outcome of social interactions. And finally, the interaction style chosen may be crucial when predicting the result of the interaction process.

\section{Evaluative Criteria}

The fourth dimension refers to the criteria chosen for the evaluation of interactive cognition. The interaction process can be described and evaluated on a cognitive and/ or a socio-emotional level. In social-psychological group research the emphasis has been on the socio-emotional level whereas in developmental psychological investigations the focus more often has been on the cognitive level of analysis. 


\section{An Experimental Study of the Interactive Minds Paradigm}

Preceding theoretical discussions provided the basis for the development of an empirical paradigm to study interactive minds. Wisdom-related knowledge and judgment was chosen as an example area in which the effect of interactive minds could be studied. In the following, the experimental paradigm developed to assess the effect of a social-interactive context on wisdom-related performance will be presented. Wisdom was chosen as a sample case to study interactive minds because it is the prototype of a collective construct. Wisdom could not develop outside of a human community. Multiple lives are necessary to be compared for wisdom-related knowledge to arise. Wisdom also is usually asked for in interactive situations and wisdom can only be recognized by others. The isolated individual could not be wise because no one could assign wisdom to this person. Finally, wisdom is a body of knowledge that may be too large and complex to be fully represented in the mind of one person. Before the social-interactive wisdom paradigm is introduced, however, it seems necessary as a frame of reference to describe the person-centered paradigm previously employed to assess wisdom-related knowledge.

Wisdom has been defined as an expert knowledge system in the fundamental pragmatics of life (e.g., Baltes and Staudinger, 1993). This is a large body of knowledge and heuristics concerned with the mastery of difficult and uncertain problems related to life conduct and the meaning of life. Wisdom is defined as superior knowledge of how to act for one's own good, that of others, and that of society. Wisdom becomes manifest in sound judgment and exceptional insight into difficult life problems. The concept of wisdom is restricted to the expertlevel products of performances whereas any lower levels are denoted by the term wisdom-related knowledge. The elicitation of wisdom puts very high demands on knowledge and judgment. Thus, one may even argue that wisdom by definition will rarely be found in a single individual, but rather in contexts which are constituted by multiple interacting minds.

To gain access to participants' knowledge systems about the fundamental pragmatics of life, three areas of thinking about the conduct and meaning of life - life planning, life review, and existential life management - were selected (see Baltes, Smith, and Staudinger, 1992, for more details). Short problem vignettes describing scenarios covering these areas were developed. These scenarios vary by age of problem character, by the typicality or normativeness of the problem, and by the targeted life domain. In terms of an experimental setting, participants first get some training in thinking aloud (Ericsson and Simon, 1984) and in dealing with this type of task. Then they are given the wisdom task describing a problem scenario of a difficult and uncertain life situation of a fictitious person, and are asked to spontaneously think aloud about the problem, such as what to consider and how to react when a friend calls and threatens to commit suicide. The tape- 
recorded and later transcribed verbatim records are then evaluated on the five wisdom-related crtiteria that are 1) Rich factual knowledge about life, 2) rich procedural knowledge about life, 3) lifespan contextualism, 4) value relativism, and 5) recognition and management of uncertainty (see Baltes, Smith, and Staudinger, 1992). The evaluation of responses is carried out by an expert rater panel. Results revealed good interrater reliabilities with Cronbach alphas ranging from .7 to .98 .

In the attempt to move beyond person-centered paradigms, the goal was to explore under which assessment conditions - involving cognitive as well as emotional and motivational processes - social interaction would either support or hinder the activation of wisdom-related knowledge and judgment. One starting point of consideration was the question how people usually deal with difficult life problems that require a certain amount of wisdom-related knowledge. In a pilot study, it was found that people distinguish at least four ways of dealing with difficult life problems (Staudinger and Baltes, 1996): (a) thinking about them by themselves, (b) consulting other people whom they consider especially helpful, or (c) taking into consideration what other people whose advice is usually sought might say to this problem, or (d) «consulting» informational sources potentially helpful for the problem at hand, be it books or long-term memory. These four conditions vary along a dimension which was labeled above as proximity of social interaction - a dimension ranging from actual interactions between two people through symbolic interaction with mental products of other people (cultural artifacts). Along this dimension one can distinguish between two basic forms of interactive minds. The first and most proximal condition is the external dialogue (subsequently referred to as external dialogue plus individual appraisal) between at least two persons actually present. The second condition on the distal end of this dimension refers to one person having an internal dialogue or virtual dialogue (subsequently referred to as internal dialogue) with the mental representation that he or she has of another person's opinion or knowledge system.

Based on these pilot results and the study of the group problem literature in social psychology, five experimental settings were developed. In the following they are described in the order of their assumed facilitative effect on wisdom-related performance (for more details of the study see Staudinger and Baltes, 1996). The greatest increase in performance was expected for the experimental condition called "dialogue plus individual appraisal». This experimental condition first provides a natural dyad with the opportunity to discuss a wisdom task in any way they like for 10 minutes. Then each member has 5 minutes to think about the task on their own in separate rooms before each is asked to respond individually. The second setting, called internal dialogue, provided for a 10 minute period in which each individual participant was asked to think about the wisdom task taking into consideration what other people, whose advice they valued, might have to say about the problem. A lower performance increase than for the two conditions just described was expected for the "dialogue» and «inner mono- 
logue» condition. In the «dialogue» condition, a natural dyad had 10 minutes to discuss a wisdom task the way they like. Immediately afterward they were asked to respond individually. The «inner monologue» condition provided for $10 \mathrm{~min}-$ utes of individual thinking time after the participant had been presented with the wisdom task. Finally, the lowest wisdom-related performances were expected of the traditional standard wisdom procedure, in which the participant was asked to think aloud by himself immediately after being presented with the wisdom task.

These five experimental conditions were applied to a sample consisting of 122 natural dyads. Thus, there were a total of 244 participants (148 women, 96 men). The sample, recruited with the assistance of a German survey research company, was very heterogeneous, with regard to education level, occupation, and the adult age range, about half were younger adults (20-44 years), and half were older adults (45-70 years; for more detail of sample composition see Staudinger and Baltes, 1996).

Three wisdom-related tasks were used to assess wisdom-related knowledge and judgment. The first task, called suicide task, describes a situation in which a person receives a call from a good friend who communicates his or her decision to commit suicide. The second was a life-review task in which a fictitious person is confronted with a meaning-of-life question. The third task was a non-normative life-management problem that dealt with a young girl who wanted to move out of her parents' home.

Analysis of variance demonstrated that the dialogue and individual appraisal condition as well as the inner dialogue condition showed performance levels one standard deviation higher than the standard condition. The inner monologue condition produced significantly lower levels of performance than those two. And the dialogue and the standard condition demonstrated the lowest level of performance, and did not differ from each other. No main effects or interaction with gender were found (for statistical details of the study see Staudinger and Baltes, 1996).

This first study implementing a social-interactive paradigm to investigate wisdom-related performance seems to offer some support in disentangling the contribution of individual and interactive components of cognition on wisdomrelated performance. The setting combining interactive and individual cognition, that is, dialogue and individual appraisal, increased performance levels by one standard deviation, whereas the dialogue condition that gives primacy to actual interactive cognition did not significantly increase performance as compared with traditional person-centered wisdom paradigms. It seems that performance settings, to be most facilitative of wisdom-related performance, should include an ideal balance between interactive and individual components of cognition. According to the findings of the study, it does not seem to make a difference whether two interacting partners actually interact with each other (proximity of interaction) or whether this interaction is mediated through mental representations of other person's advice. Actually symbolically mediated interac- 
tion may even have the advantage of leaving it open to the person to decide when to access or use another person's knowledge system thus providing for better coordination and minimized socioemotional discordances.

\section{Discussion and Conclusion}

In sum, the overall outcome of the first study lend support to the guiding theoretical perspectives. The results supported the view that wisdom-related performance profits from certain social-interactive contexts. Thus, any performance setting that ignores the interactive-minds aspect of wisdom underestimates wisdom-related performance capacity. The outcome pattern across the five experimental conditions was largely consistent with the predictions. As predicted, the two interactive-minds conditions (external dialogue plus individual appraisal, internal dialogue) that were judged to carry special ecological relevance and functionality significantly increased wisdom-related performance levels. The overall facilitative effect of the two ecologically relevant and, according to theoretical assumptions, functional conditions involving interactive minds (external dialogue plus individual appraisal, internal dialogue) was substantial.

The two control conditions, which did not prompt for the interaction of minds (individual-thinking-time condition and standard condition), showed only low or no performance increases. In the third control condition (external dialogue without individual thinking time), which was judged to be less ecologically relevant and functional, participants also behaved as predicted. From a theoretical point of view, this condition was judged to be less effective due to the lack of opportunity to reflect about the information exchanged and activated during the dyadic discussion. In sum, the basic hypothesis of this attempt to approach the study of wisdom using interactive-minds settings was supported.

With regard to the theoretical claim of symbolic interactionism (e.g., Mead, 1934; Vygotsky, 1978) and related interpretations (e.g., Baltes and Staudinger, 1996; Rogoff and Chavajay, 1995; Wertsch, 1991), it is interesting to note that interaction with others can be external as well as internal. Interaction with the mental representation of other persons' knowledge (internal dialogue) was as powerful a facilitator of wisdom-related performance as was actual social interaction with another person when subsequent individual thinking time was provided. It can not be known of course, whether the processes associated with internal and external exchanges between interacting minds are similar. What can be derived from the study is that both conditions produced significant performance enhancements. It seems critical that future researchers create experimental settings in which both conditions are presented in various combinations and sequences to decompose the separate and joint effects of interactive minds associated with internal and external exchanges. 
One may wonder why the external dialogue between members of a natural dyad (without supplementary individual thinking time) did not produce higher levels of wisdom-related performance. As argued earlier, the design carried this performance setting as control condition and it was therefore expected to result in lower performance increases than the two experimental conditions (external dialogue plus, internal dialogue). The failure to produce performance increases might have been due to the absence of an opportunity for further thought processes about the dialogue. This can be inferred from the fact that the external-dialogue-plus condition produced not just a performance enhancement effect, but the strongest one. Therefore, it seems that in the external-dialogue-plus condition, participants had the possibility to integrate ideas raised during discussion. This finding is in line with research on the effect of collaboration on cognitive development in childhood and adolescence (cf. Azmitia, 1996; Rogoff and Chavajay, 1995). These studies showed that it is not during the interaction between peers or between adult and child that improvements in cognitive performance are observed, rather, improvements are observed subsequently, during the child's individual performance.

Taking wisdom-related performance as a sample case, it was demonstrated that by restricting research to the isolated individual without referring to factual or «virtual» exchanges with other minds, one is likely to underestimate cognitive performance potential. When comparing the performance levels under interactive-minds conditions with results obtained in earlier work (cited above) a window on the cognitive potential seems to be opened. Future research should include social-interactive paradigms in the study of many developmental domains to do better justice to the social nature of human kind.

\section{Notes}

1 The data reported in this article were collected as part of the project «Wisdom and Lifespan Development» conducted at the Max Planck Institute for Human Development and Education, codirected by Paul B. Baltes and Ursula M. Staudinger (1992-1999). We gratefully acknowledge the assistance in data collection and organization by Susanne Böhmig, Marcel Braß, Simone Elsing, Gabi Faust, Claudia v. Grothe, Kerstin Haenel, Irmgard Pahl, and Gisela Schubert.

\section{References}

Azmitia, M. (1996). Peer interactive minds: Developmental, theoretical, and methodological issues. In Baltes, P. B., Staudinger, U. M., \& et al. (Eds.), Interactive minds: Life-span perspectives on the social foundation of cognition (pp. 133-162). New York: Cambridge University Press.

Azmitia, M., \& Perlmutter, M. (1989). Social influences on children's cognition: State of the art and future directions. Advances in Child Development and Behavior, 22, 89-144.

Baltes, P.B. (1987) Theoretical propositions of life-span developement psychology: On the dynamics between growth and decline. Developement Psychology, 23, 611-626.

Baltes, M. M. (1995). Dependency in old age: Gains and losses. Current Directions in Psychological Science, 4, 14-19. 
Baltes, P. B., \& Kliegl, R. (1992). Further testing of limits of cognitive plasticity: Negative age differences in a mnemonic skill are robust. Developmental Psychology, 28(1), 121-125.

Baltes, P. B., Reese, H. W., \& Lipsitt, L. P. (1980). Life-span developmental psychology. Annual Review of Psychology, 31, 65-110.

Baltes, P. B., Smith, J., \& Staudinger, U. M. (1992). Wisdom and successful aging. In Sonderegger, T. B., \& et al. (Eds.), Nebraska symposium on motivation 1991: Psychology and aging. Current theory and research in motivation, Vol. 39 (pp. 123-167). Lincoln, NE: University of Nebraska Press.

Baltes, P. B., \& Staudinger, U. M. (1993). The search for a psychology of wisdom. Current Directions in Psychological Science, 2(3), 75-80.

Baltes, P. B., \& Staudinger, U. M. (Eds.) (1996). Interactive minds: Life-span perspectives on the social foundation of cognition. New York, NY: Cambridge University Press.

Baltes, P. B., Staudinger, U. M., \& Lindenberger, U. (1999). Life-span developmental psychology. Annual Review of Psychology, 50, 471-507.

Baltes, P. B., Staudinger, U. M., Maercker, A., \& Smith, J. (1995). People nominated as wise: A comparative study of wisdom-related knowledge. Psychology and Aging, 10(2) 155-166.

Bandura, A. (1986). Social foundations of thought and action: A social cognitive theory. Englewood Cliffs, NJ: Prentice-Hall.

Bar Tal, D. , \& Kruglanski, A. W. (Eds.) (1988). The social psychology of knowledge. Cambridge: Cambridge University Press.

Barkow, J. H., Cosmides, L. , \& Tooby, J. (Eds.) (1992). The adapted mind: Evolutionary psychology and the generation of culture. New York: Oxford University Press.

Boesch, E. E. (1991). Symbolic action theory and cultural psychology. Heidelberg: Springer.

Bornstein, M. H., \& Bruner, J. S. (Eds.) (1989). Interaction in human development. Hillsdale, NJ: Erlbaum.

Brown, A. L., Campione, J. C., Webber, L. S., \& McGilly, K. (1992). Interactive learning environments: A new look at assessment and instruction. In Gifford, B. R., O'Connor, M. C. , \& et al. (Eds.), Changing assessments: Alternative views of aptitude, achievement and instruction. Evaluation in education and human services (pp. 121-211). Boston, MA: Kluwer Academic Publishers.

Cohen, R. , \& Siegel, A. W. (Eds.) (1991). Context and development. Hillsdale, NJ: Erlbaum.

Cole, M. (1996). Interacting minds in a life-span perspective: A cultural-historical approach to culture and cognitive development. In Baltes, P. B., Staudinger, U. M., \& et al. (Eds.), Interactive minds: Life-span perspectives on the social foundation of cognition (pp. 59-87). New York: Cambridge University Press.

von Cranach, M. , Doise, W. , \& Mugny, G. (Eds.) (1992). Social representations and the social bases of knowledge. Lewiston, NY: Hogrefe and Huber Publishers.

Cosmides, L. (1989). The logic of social exchange: Has natural selection shaped how humans reason? Cognition, 31, 187-276.

Dixon, R. A. (1992). Contextual approaches to adult intellectual development. In Sternberg, R. J., Berg, C. A., \& et al. (Eds.), Intellectual development (pp. 350-380). New York: Cambridge University Press.

Dixon, R. A., \& Gould, O. N. (1996). Adults telling and retelling stories collaboratively. In Baltes, P. B. \& Staudinger, U. M. (Eds.), Interactive minds: Life-span perspectives on the social foundation of cognition (pp. 221-241). New York: Cambridge University Press.

Endler, N. S., \& Magnusson, D. (Eds.) (1976). Interactional psychology and personality. Washington: Hemisphere.

Ericsson, K. A., \& Simon, H. A. (1984). Protocol analysis: Verbal reports as data. Cambridge, MA: MIT Press.

Fiske, A. P. (1992). «The four elementary forms of sociality: Framework for a unified theory of social relations.» Psychological Review 99(4), 689-723. 
Forman, E. A., Minick, N. , \& Stone, C. A. (Eds.) (1993). Contexts for learning: Sociocultural dynamics in children's development. New York: Oxford University Press.

Francescato, G. (1973). Spracherwerb und Sprachstruktur beim Kinde. Stuttgart: Klett.

Gigerenzer, G. (1996). Rationality: Why social context matters. In P. B. Baltes \& U. M. Staudinger (Eds.), Interactive Minds. Life-span perspectives on the social foundation of cognition (pp. 317-346). Cambridge, Cambridge University Press.

Heckhausen, J., Dixon, R. A., \& Baltes, P. B. (1989). Gains and losses in development throughout adulthood as perceived by different adult age groups. Developmental Psychology, 25(1), 109-121.

Hill, G. W. (1982). Group versus individual performance: Are N+1 heads better than one? Psychological Bulletin, 91, 517-539.

Kahn, R. L., \& Antonucci, T. C. (1980). Convoys over the life course: Attachment, roles, and social support. In P. B. Baltes \& Jr O. G. Brim (Eds.), Life-span development and behavior (Vol. 3, pp. 253-286). New York: Academic Press.

Leary, D. E. (Ed.) (1990). Metaphors in the history of psychology. New York: Cambridge University Press.

Levine, J. M., Resnick, L. B., \& Higgins, E. T. (1993). Social foundations of cognition. Annual Review of Psychology, 44, 585-612.

Light, P. , \& Butterworth, G. (Eds.). (1992). Context and cognition: Ways of learning and knowing.

Mead, G. H. (1934). Mind, self, and society. Chicago, IL: Chicago University Press.

Miller, D. T., \& Prentice, D. A. (1994). Collective errors and errors about the collective. Personality and Social Psychology Bulletin, 20(5), 541-550.

Neimeyer, R. A., Neimeyer, G. J., Lyddon, W. J., \& Hoshmand, L. T. (1994). Review: The reality of social construction. Contemporary Psychology, 39, 459-463.

Perlmutter, M. (Ed.) (1990). Late-life potential. Washington, D.C.: Gerontological Society of America.

Resnick, L. B., Levine, J. M., \& Teasley, S. D. (Eds.) (1991). Perspectives on socially shared cognition. Washington, D.C.: American Psychological Association.

Rogoff, B., \& Chavajay, P. (1995). What's become of research on the cultural basis of cognitive development? American Psychologist, 50(10), 859-877.

Salthouse, T. A. (1991). Theoretical perspectives on cognitive aging. Hillsdale, NJ: Erlbaum.

Staudinger, U. M. (1996). Wisdom and the social-interactive foundation of the mind. In Baltes, P. B., Staudinger, U. M., \& et al. (Eds.), Interactive minds: Life-span perspectives on the social foundation of cognition (pp. 276-315). New York: Cambridge University Press.

Staudinger, U. M., \& Baltes, P. B. (1994). The psychology of wisdom. In R. J. Sternberg et. al. (Eds.), Encyclopedia of intelligence (pp. 1143-1152). New York: Macmillan.

Staudinger, U. M., \& Baltes, P. B. (1996). Interactive minds: A facilitative setting for wisdomrelated performance? Journal of Personality and Social Psychology, 71(4), 746-762.

Staudinger, U. M., Smith, J., \& Baltes, P. B. (1992). Wisdom-related knowledge in a life review task: Age differences and the role of professional specialization. Psychology and Aging, $7(2), 271-281$.

Sternberg, R. J. (1990a). Metaphors of mind: Conceptions of the nature of intelligence. New York: Cambridge University Press.

Sternberg, R. J. (Ed.) (1990b). Wisdom. Its nature, origins, and development. New York: Cambridge University Press.

Sternberg, R. J., \& Wagner, R. K. (Eds.) (1994). Mind in context: Interactionist perspectives on human intelligence. New York: Cambridge University Press.

Stroebe, W., Diehl, M., \& Abakoumkin, G. (1992). The illusion of group effectivity. Personality and Social Psychology Bulletin, 18(5), 643-650.

Vygotsky, L. S. (1978). Mind in society: The development of higher psychological processes. Cambridge, MA: Harvard University Press. 
Wegner, D. M., Erber, R., \& Raymond, P. (1991). Transactive memory in close relationships. Journal of Personality and Social Psychology, 61(6), 923-929.

Wertsch, J. V. (1991). Voices of the mind: A sociocultural approach to mediated action. Cambridge, MA: Harvard University Press.

Wozniak, R. H., \& Fischer, K. W. (Eds.) (1993). Development in context: Acting and thinking in specific environments. Hillsdale, NJ: Erlbaum.

Wyer, R. S., \& Srull, T. K. (1986). Human cognition in its social context. Psychological Review, 93(3), 322-359.

\section{"Interactive minds" - Ein Paradigma zur Erforschung der sozial-interaktiven Natur menschlicher Kognitionen und ihrer lebenslangen Entwicklung}

\section{Zusammenfassung}

Nach einem kurzen Überblick über historische sowie aktuelle Entwicklungen in der Forschung zur sozial interaktiven Natur des Denkens, wird eine Definition des «interactive minds» Paradigmas vorgestellt. In mindestens dreierlei Hinsicht sind Kognitionen von Natur aus sozial interaktiv: (a) in ihrer kulturellen Evolution und ihrer Ontogenese (b) in ihrer Aktivierung und Anwendung (c) und in ihrer Bewertung. Aber ist es immer wahr, daß zwei Köpfe besser sind als einer? Ein empirisches «interactive minds» Paradigma wurde entwickelt und beispielhaft im Bereich des weisheitsbezogenen Wissens überprüft. Fünf Versuchsbedingungen, die sich im Verhältnis individueller und interaktiver Kognitionen, sowie ihrer ökologischen Relevanz unterschieden, wurden entwickelt. Die Ergebnisse zeigten, daß die Bedingung, die aus einer Kombination sowohl individueller als auch interaktiver Kognitionen bestand, am förderlichsten für die Aktivierung weisheitsbezogenen Wissens und Urteilens war. Es scheint, daß nicht jede interaktive Kognition förderlich ist, sondern eher eine sequentielle Kombination aus individuellen und interaktiven Kognitionen.

\section{"Interactive Minds" - Un paradigme pour l'étude de la nature socio-interactive de la cognition humaine et de son développement tout au long de la vie}

\section{Résumé}

Après un bref aperçu des tendances historiques et contemporaines dans l'étude de la nature socio-interactive de la cognition, une définition du paradigme «interactive minds» est présentée. La cognition est socio-interactive sous au moins trois points de vue : a) dans son évolution culturelle de même que dans son ontogenèse; b) dans ses modes d'activation et d'application; c) dans sa prise en compte. Mais est-il toujours vrai que deux têtes valent mieux qu'une? Pour abor- 
der ces questions, le paradigme «interactive minds» a donné lieu à une recherche dans le domaine des «connaissances reposant sur la sagesse». Cinq conditions expérimentales ont été construites qui différaient dans le rapport entre cognition individuelle et interactive ainsi que sur le plan de leur pertinence écologique.

Les résultats ont montré que la condition combinant cognitions individuelle et interactive, c'est-à-dire dialogue et jugement, était la plus à même d'activer les «connaissance liées à la sagesse» et le jugement. Ainsi, il semble que la solution la plus efficace n'est pas une cognition interactive mais bien plutôt une combinaison séquentielle aussi bien d'une cognition individuelle et interactive.

\section{"Interactive minds" - Un paradigma per l'esplorazione della natura socialmente interattiva della cognizione umana e del suo sviluppo durante l'esistenza}

\section{Riassunto}

Dopo una breve sintesi degli sviluppi storici e attuali nella ricerca attorno alla natura interattiva della cognizione umana, si propone una definizione del paradigma «interactive minds». L'attività cognitiva si rivela essere socialmente interattiva almeno da tre punti di vista: a) nel suo sviluppo culturale e nella sua ontogenesi, b) nella sua attivazione e attuazione e c) nella sua valutazione. Ma è sempre vero che due teste sono meglio di una? Il paradigma empirico «interactive minds» è stato sperimentato nell'ambito del sapere che si mette in relazione alla saggezza. Partendo da 5 situazioni sperimentali, diverse per il coinvolgimento individuale e sociale dei soggetti e per la loro rilevanza ecologica, si è constatato che l'attivazione del sapere e della capacità di giudizio basata sulla saggezza è migliore quando sussiste una combinazione di elementi cognitivi individuali e sociali. Sembra che non ogni situazione di interazione favorisca l'attività cognitiva, quanto piuttosto appunto una combinazione sequenziale di elementi individuali e sociali. 